\title{
Management of Treatment-Resistant Depression in Real-World Clinical Practice Settings Across
}

Asia

This article was published in the following Dove Press journal:

Neuropsychiatric Disease and Treatment

Gang Wang, ${ }^{1,2}$ Changsu Han, (D) ${ }^{3}$ Chia-Yih Liu, (D) ${ }^{4}$ Sandra Chan, ${ }^{5}$ Tadafumi Kato, $\mathbb{B D}^{6,7}$

Wilson Tan, (1) ${ }^{8}$ Lili Zhang, (D) 9 Yu Feng, ${ }^{9}$ Chee $\mathrm{H} \mathrm{Ng} \mathbb{D}^{10}$

'The National Clinical Research Center for Mental Disorder \& Beijing Key Laboratory of Mental Disorders, Beijing Anding Hospital, Capital Medical University, Beijing, People's Republic of China; ${ }^{2}$ Advanced Innovation Center for Human Brain Protection, Capital Medical University, Beijing, People's Republic of China; ${ }^{3}$ Department of Psychiatry, Korea University College of Medicine, Seoul, South Korea; ${ }^{4}$ Department of Psychiatry, Chang Gung Medical Center, and Chang Gung University School of Medicine, Taoyuan City, Taiwan; ${ }^{5}$ Department of Psychiatry, The Chinese University of Hong Kong, Hong Kong, People's Republic of China; ${ }^{6}$ RIKEN Center for Brain Science, Wako, Saitama, Japan; ${ }^{7}$ Department of Psychiatry and Behavioral Science, Juntendo University Graduate School of Medicine, Tokyo, Japan; ${ }^{8}$ Regional Medical Affairs, Janssen Pharmaceutical Companies of Johnson and Johnson, Singapore, Singapore; ' $M$ Medical Affairs, Xian Janssen Pharmaceutical Ltd, Beijing, People's Republic of China;

${ }^{10}$ Department of Psychiatry, The University of Melbourne, Melbourne, Victoria,

Australia

Correspondence: Chee $\mathrm{H} \mathrm{Ng}$

The Melbourne Clinic, I 30 Church Street,

Richmond, Victoria 3I2I, Australia

$\mathrm{Tel}+61394209350$

Fax +6I 394210704

Email cng@unimelb.edu.au

Wilson Tan Regional Medical Affairs, Janssen Pharmaceutical Companies of Johnson and Johnson, 2 Science Park Drive, \#07-13, Ascent, Singapore Science

Park I, I I8222, Singapore

Tel +65-69187930

Email wtan27@its.jnj.com
Purpose: Consensus is lacking on the management of treatment-resistant depression (TRD), resulting in significant variations on how TRD patients are being managed in real-world practice. A survey explored how clinicians managed TRD across Asia, followed by an expert panel that interpreted the survey results and provided recommendations on how TRD could be managed in real-world clinical settings.

Methods: Between March and July 2018, 246 clinicians from Hong Kong, Japan, Mainland China, South Korea, and Taiwan completed a survey related to their treatment approaches for TRD. Results: The survey showed physicians using more polytherapy (71\%) compared to maintaining patients on monotherapy (29\%). The most commonly (23\%) administered polytherapy involved antidepressant augmentation with antipsychotics that $19 \%$ of physicians also indicated as their most important approach for managing TRD. The highest number of physicians (34\%) ranked switching to another class of antidepressants as their most important approach, while $16 \%$ and $9 \%$ chose antidepressant combinations and electroconvulsive therapy (ECT), respectively.

Conclusion: Taking into account the survey results, the expert panel made general recommendations on the management of TRD. TRD partial-responders to antidepressants should be considered for augmentation with second-generation antipsychotics. For non-responders, switching to another class of antidepressants ought to be considered. TRD patients achieving remission with acute treatment should consider continuing their antidepressants for at least another 6 months to prevent relapse. ECT is a treatment consideration for patients with severe depression or persistent symptoms despite multiple adequate trials of antidepressants. Physicians should also consider the response, tolerability and adherence to the current and previous antidepressants, the severity of symptoms, comorbidities, concomitant medications, preferences, and cost when choosing a TRD treatment approach for each individual patient. Keywords: Asia, treatment-resistant depression, diagnosis, management

\section{Introduction}

Globally, there is a lack of consensus on the definition of treatment-resistant depression (TRD). ${ }^{1}$ A recent expert panel defined TRD as a condition that affects patients with major depressive disorder (MDD) experiencing a failure to $\geq 2$ antidepressant therapies given at adequate doses for 6-8 weeks during a major depressive episode. ${ }^{2}$ TRD is a major cause of disability, morbidity, and mortality worldwide incurring considerable economic and social burden, especially for the non-responders compared to those who respond to some form of treatment. ${ }^{3-5}$ 
Prevalence studies on TRD adopted various TRD definitions resulting in large variations in estimations. In the Sequenced Treatment Alternatives to Relieve Depression (STAR*D) trial, around $30 \%$ of MDD patients remained symptomatic despite multiple lines of antidepressant treatments. ${ }^{6}$ Using the Taiwan National Health Insurance Research database, the proportion of pharmaceutically treated depression (PTD) who developed TRD was about $21 \%$, with an incidence rate of 0.82 cases per 1000 population in $2005 .^{7}$ Using a similar TRD definition of $\geq 2$ antidepressant failures, the proportion of PTD patients developing TRD was estimated to be about $4.2 \%$ $(34,812 / 834,694)$ and $12.0 \%(137 / 1143)$ in $\mathrm{Korea}^{8}$ and Japan, ${ }^{5}$ respectively. Certainly, differences in study methodology (for example, prospective, multi-site, randomized STAR*D clinical trial vs retrospective databases analyses for Taiwan, Korea, and Japan) and healthcare systems could also have contributed to the differences in prevalence estimates illustrated above.

Another downstream consequence of a lack of consistency in the definition of TRD is the high variability in treatment approaches for TRD. ${ }^{9,10}$ This is further aggravated by the paucity of TRD-specific scientific evidence and treatment guidelines. In general, TRD management requires an integrated approach that may involve various combinations of pharmacotherapy, somatic treatments [for example, electroconvulsive therapy (ECT) and transcranial magnetic stimulation (TMS)], psychotherapy, and social support. ${ }^{9}$

There is limited information on how TRD is being managed by clinicians in real-world settings across Asia. Hence, a cross-sectional survey was conducted to examine the different approaches adopted by Asian physicians in managing TRD during their day-to-day clinical practice. In addition to the survey, this article includes practical recommendations developed by an expert panel, based on current evidence and clinical practice guidelines while taking into account the survey results. Pharmacotherapy, which is the cornerstone of the treatment of $\mathrm{TRD},{ }^{9,10}$ is a major focus of this article.

This article constitutes the final part of a larger research project composed of three phases. In Phase 1, a consensus on the definition of TRD was developed from an Asia-Pacific perspective that is now published. ${ }^{2,11}$ In Phase 2, we sought to understand how TRD patients were being diagnosed and identified by Asian physicians in their routine clinical practice. That article was under review at the time of developing this current manuscript (Han et al, Definition and identification of patients with treatment-resistant depression in realworld clinical practice settings across Asia). Here, Phase 3 focused on the treatment of TRD in Asia. A crosssectional physician survey and subsequent expert panel contributed to Phases 2 and 3 of the research project.

Phase 3 findings are presented here in a three-part format: 1) Results of the cross-sectional survey; 2) Discussion of the survey results by an expert panel with due consideration of published evidence and treatment guidelines; and 3) Expert Recommendations in consideration of the survey findings.

\section{Methods}

The methodology for the cross-sectional survey and expert panel will only be briefly described here. Additional relevant details are provided in Supplement 1, but the full methodology is described in a separate article (Han et al, Definition and identification of patients with treatmentresistant depression in real-world clinical practice settings across Asia).

\section{Cross-Sectional Physician Survey Survey Sites}

A cross-sectional survey was conducted between March and July 2018, enlisting sites that employed practicing physicians with substantial clinical experience and are actively managing patients with depression, especially those with MDD, from South Korea (39 sites), Taiwan (30 sites), Mainland China (20 sites), Japan (17 sites) and Hong Kong (15 sites).

\section{Survey Participants}

Surveyed physicians were required to have $\geq 5$ years of clinical experience in treating patients with MDD and are currently still treating MDD patients in a typical month with $\geq 1$ patient having TRD. Informed consent was obtained from eligible participants prior to conducting the face-toface survey. Two hundred and forty-six physicians participated in the survey; 80 (33\%) of whom were from Mainland China, 65 (26\%) from South Korea, 60 (24\%) from Taiwan, 24 (10\%) from Hong Kong, and 17 (7\%) from Japan. Threequarters $(74 \%)$ were male and $54 \%$ were practicing in the public health sector. Approximately $54 \%$ of the physicians were self-reported as "senior consultant level or above". The mean duration of MDD-related clinical experience was 17 years. More details on survey respondents can be found in Supplement 1. 


\section{Survey Data Collection and Analyses}

The survey, comprising open- and close-ended questions, was translated by professional translation service providers. The translated questionnaires were then pilot tested in different participating countries before being fully implemented. The questionnaires were administered by interviewers from a contract research organization. Responses from survey participants, collected in their local language, were translated into English before data entry. Descriptive analyses were conducted using Stata version 15 (StataCorp, 2017). ${ }^{12}$ Transcribed data were also analyzed using thematic analysis. Salient themes were identified by two coders independently using NVivo version 11 (QSR International, $2017)^{13}$ before meeting to agree on the final themes. More details on how the survey data were analyzed can be found in Supplement 1. Survey questions related to this article are included in Supplement 2.

\section{Survey Ethics Review}

Ethics clearance was obtained from the Chinese University of Hong Kong (Hong Kong), the Japanese Association of the Promotion of State-of-art in Medicine (Japan), Anding Hospital (Mainland China), Korea University Ansan Hospital (South Korea), and Chang Gung Medical Center (Taiwan).

\section{Expert Panel}

Six senior psychiatrists, who were highly regarded as TRD experts from the Asia-Pacific region, formed a panel to discuss the survey results and provided practical recommendations on how TRD should be managed in day-to-day clinical settings in Asia. These experts are also authors of this article.

\section{Results and Discussion}

\section{Question I: TRD Pharmacotherapy -} Antidepressant Switching vs

\section{Augmentation?}

\section{Survey Results}

Participating physicians were asked to indicate their percentage use of each approach for the treatment of TRD, with all the approaches summing up to $100 \%$. As shown in Table 1, the mean use of polytherapy (71\%) was higher than switching to another monotherapy antidepressant (29\%).

\section{Discussion}

This section focuses on the acute relief of depressive symptoms among TRD patients in general. Treatment of TRD with severe symptoms (for example, increased risk
Table I Percentage of Use of Various TRD Treatment Approaches

\begin{tabular}{|l|l|}
\hline TRD Treatment Approaches & $\begin{array}{l}\text { Mean Use \% } \\
\text { (SD) }\end{array}$ \\
\hline Monotherapy (antidepressant) & $28.7 \%(29.9)$ \\
Polytherapy & $71.3 \%(29.9)$ \\
Antidepressant and antipsychotics & $31.7 \%(22.9)$ \\
Two antidepressants & $22.8 \%(19.0)$ \\
Antidepressant and anticonvulsant & $4.3 \%(0.9)$ \\
Antidepressant and mood stabilizer & $4.2 \%(0.7)$ \\
Antidepressant and electroconvulsive therapy (ECT) & $3.4 \%(0.7)$ \\
Others & \\
\end{tabular}

Note: ${ }^{a}$ Others comprise thyroid hormones, Traditional Chinese Medicine, psychotherapy, transcranial magnetic stimulation (TMS).

Abbreviation: SD, standard deviation.

of harm to self or others) and maintenance therapy for relapse/recurrence prevention are discussed further below. The survey results showed that surveyed physicians preferred augmentation with antipsychotics (32\%), to switching to $(29 \%)$ or adding $(23 \%)$ another antidepressant.

Several guidelines suggest considering the patients' response to their current antidepressant when choosing between augmentation and switching to another antidepressant. ${ }^{14-16}$ In the Phase 2 article that is currently under review, the expert panel proposed a practical definition of antidepressant treatment failure as $<50 \%$ reduction in Hamilton Depression Rating Scale (HAMD-17) or Montgomery-Åsberg Depression Rating Scale (MADRS) (Han et al, Definition and identification of patients with treatment-resistant depression in real-world clinical practice settings across Asia). Some studies have further classified this patient group into those with " $25-50 \%$ improvement (sometimes called partial-responders)" and those with " $<25 \%$ improvement (sometimes called non-responders)". 17,18

For partial-responders (with $25-50 \%$ improvement on their current antidepressants), guidelines suggest first employing augmentation to potentiate the efficacy of the current antidepressant. ${ }^{14,19}$ The evidence comparing augmentation versus switching to another antidepressant is limited and equivocal. Some studies have demonstrated augmentation with antipsychotics to be superior (in remission) to switching antidepressants. ${ }^{20-22}$ However, these studies adopted varying definitions of antidepressant treatment failure, recruited patients with $\geq 1$ antidepressant failure and did not distinguish between those who improved $<25 \%$ versus $25-50 \%$; thereby limiting its applicability for this discussion. Other evidence, on the other hand, showed comparable efficacy between 
switching and augmentation in TRD patients. ${ }^{20}$ How augmentation should be implemented is further discussed in Question 2.

For non-responders (with $<25 \%$ improvement), especially those experiencing poor tolerability to their current antidepressant, several guidelines recommend first switching to another antidepressant. ${ }^{14-16,19,23}$ The benefits of maintaining the TRD patient on monotherapy by switching to another antidepressant, instead of augmentation, include the likelihood of better adherence, fewer drug-drug interactions, and lower cost. Results from a meta-analysis involving depressed patients who failed a course of selective serotonin reuptake inhibitors (SSRI) showed significantly higher, albeit modest, remission rates among patients being switched to a nonSSRI rather than an SSRI antidepressant. ${ }^{24}$ On the other hand, a systematic review involving MDD patients with varying levels of treatment resistance showed no clear advantage for between-antidepressant-class versus withinclass switch after the first SSRI failure. ${ }^{25}$

\section{Expert Recommendations}

When choosing a TRD treatment approach, physicians should consider the patient's response, tolerability and adherence to the current and previous antidepressants, the severity of symptoms, comorbidities, concomitant medications, preferences, and cost. Consistent with current treatment guidelines, physicians should, in general, first consider augmenting the current antidepressant in the TRD patient who demonstrates a $25-50 \%$ improvement. For the TRD patient achieving $<25 \%$ improvement with their current antidepressant, consider switching to another antidepressant. Although there is no definitive evidence to suggest switching to another class of antidepressants as being more effective than switching within the same class, another class of antidepressants is recommended if the TRD patient has already demonstrated $\geq 2$ treatment failures within the same class of antidepressants. Given the lack of compelling data to suggest any one approach is unequivocally superior to the other, both switching and augmentation are reasonable for the general treatment of TRD patients.

\section{Question 2: TRD Pharmacotherapy - Approach to Antidepressant Augmentation? Survey Results}

Table 2 shows the responses from physicians when asked what treatment(s) could be added to constitute adjunctive antidepressant treatment for TRD patients. Participants were
Table 2 Approaches to Adjunctive Antidepressant Treatment in TRD

\begin{tabular}{|l|l|}
\hline Adjunctive Treatments to Antidepressants in TRD & $\mathbf{n}(\%)$ \\
\hline Antipsychotics & $229(93.1)$ \\
\hline Electroconvulsive therapy (ECT) & $129(52.4)$ \\
\hline Other Antidepressants & $28(11.5)$ \\
Selective serotonin reuptake inhibitors (SSRIs) & $10(4.1)$ \\
Serotonin-norepinephrine reuptake inhibitors (SNRIs) & $9(3.7)$ \\
Noradrenergic and specific serotonergic antidepressants (NaSSAs) & $9(3.7)$ \\
\hline Anticonvulsants & $6(2.4)$ \\
\hline Mood stabilizers & $4(1.6)$ \\
\hline
\end{tabular}

Abbreviation: TRD, treatment-resistant depression.

prompted on "antipsychotics" and "ECT"; but could include any number of other options that they deemed were applicable. About $93 \%$ of the physicians selected the addition of antipsychotics, while $52 \%$ chose ECT. Those who opted for antidepressant combinations was about $12 \%$. A much smaller proportion of physicians selected anticonvulsants (2\%) and mood stabilizers (2\%) for antidepressant augmentation.

\section{Discussion}

The most common approach to adjunctive antidepressant treatment in Asia was with antipsychotics (93.1\%), followed by ECT (52.4\%). Only 2\% of Asian physicians considered the use of mood stabilizers for augmentation.

\section{Choice of Augmentation Strategy}

Head-to-head studies comparing various augmentation and (antidepressant) combination treatments are limited, but generally showed comparable efficacy between antipsychotics, lithium, thyroid hormone, and add-on antidepressants. $^{26,27} \mathrm{~A}$ recent systematic review and network meta-analysis (NMA) was conducted to determine the relative effectiveness (using effect sizes, ES) of augmentation treatments for adult TRD. ${ }^{28}$ This NMA sought all randomized trials of pharmacological and psychological augmentation interventions but none of the psychological trials met its inclusion criteria. The direct evidence estimated a pooled ES $=0.29(95 \%$ CI $0.21-0.37$; $\left.\mathrm{p}<0.001 ; \mathrm{I}^{2}=99 \%\right)$ for antipsychotics vs placebo (13 studies), ES $=0.07\left(95 \% \mathrm{CI}-0.18-0.33 ; \mathrm{p}<0.57 ; \mathrm{I}^{2}=\right.$ $22 \%$ ) for mood stabilisers vs placebo ( 3 studies), ES = 0.91 (95\% CI $\left.0.67-1.16 ; \mathrm{p}<0.001 ; \mathrm{I}^{2}=77 \%\right)$ for N-methylD-aspartate (NMDA) antagonists vs placebo (5 studies). ${ }^{28}$ The authors of this NMA suggested NMDA therapies as having the "highest chance of being an effective treatment 
option compared to other pharmacological classes". However, the authors did acknowledge the limited ability to draw definitive conclusions due to the heterogeneity (substantial heterogeneity defined as $\mathrm{I}^{2}>60 \%$ ) across a small number of included trials. It is also noteworthy that three out of the five NMDA studies involved ketamine use, which is currently a controlled substance and not therapeutically indicated for TRD across most parts of Asia. Ketamine is discussed in more detail under Question 3. In another recent systematic review and metaanalysis, the NMDA-targeting drugs also demonstrated the highest $\mathrm{ES}=1.48\left(95 \%\right.$ CI $\left.1.25-1.71 ; \mathrm{I}^{2}=0 \%\right)$ compared with antipsychotics [ES $=1.12\left(95 \%\right.$ CI $0.98-1.26 ; \mathrm{I}^{2}$ $=75 \%)$, mood stabilisers [ES $=1.12(95 \%$ CI 0.92-1.31; $\left.\mathrm{I}^{2}=23.6 \%\right)$ ] and thyroid hormones [ES $=1.15(95 \% \mathrm{CI}$ $\left.\left.0.79-1.52 ; \mathrm{I}^{2}=\mathrm{N} / \mathrm{A}\right)\right] .{ }^{29}$ In this second meta-analysis, the ES across classes appears more similar with overlapping confidence intervals. Three lithium studies included in this second meta-analysis contributed to an estimated ES $=1.00\left(95 \%\right.$ CI $\left.0.81-1.20 ; \mathrm{I}^{2}=0 \%\right)$.

The efficacy of lithium as an augmentation therapy for TRD patients has been well-established via randomized controlled trials (RCTs). ${ }^{30}$ However, majority of these studies involved augmenting tricyclic antidepressants (TCA). Evidence on the use of lithium as an add-on therapy to current antidepressants (eg, SSRI and SNRI) is more limited, but nevertheless available. ${ }^{31-33}$ Lithium toxicity, described in the boxed warning of its prescribing information, is closely related to its serum concentration. The multiple drug-drug interactions, together with its risks of toxicity, require serum lithium concentration to be monitored frequently. ${ }^{34}$

Thyroid hormones as augmentation therapy in TRD patients have been even less studied and mainly involved augmenting TCAs. These findings may be relevant given SSRIs, like escitalopram, fluoxetine, fluvoxamine, paroxetine, and sertraline, are commonly used and recommended as first-line agents across multiple countries in Asia. $^{35}$ Evidence supporting the use of antidepressant combinations and their comparative effectiveness is relatively limited. ${ }^{36}$ There is also some limited evidence on the use of buspirone, lamotrigine, pindolol, modafinil, and traditional psychostimulants as augmentation agents. ${ }^{37}$

\section{Choice of Second-generation Antipsychotic}

There is currently no high-quality head-to-head data to suggest one second-generation antipsychotic as being superior to another for TRD antidepressant augmentation.
The above meta-analysis estimated the effect sizes for aripiprazole (4 studies), brexpiprazole (2 studies), ziprasidone (1 study), risperidone (1 study), quetiapine (1 study) and olanzapine (1 study). ${ }^{29}$ The effect size appeared highest with aripiprazole $\left[\mathrm{ES}=1.33\left(95 \%\right.\right.$ CI 1.23-1.44; $\mathrm{I}^{2}$ $=0 \%)]$ compared with brexpiprazole $[\mathrm{ES}=0.96(95 \% \mathrm{CI}$ $\left.0.85-1.06 ; \mathrm{I}^{2}=17.3 \%\right)$, ziprasidone $[\mathrm{ES}=0.65(95 \% \mathrm{CI}$ $\left.\left.0.31-0.99 ; \mathrm{I}^{2}=\mathrm{N} / \mathrm{A}\right)\right]$, risperidone $[\mathrm{ES}=1.15(95 \% \mathrm{CI}$ $\left.\left.0.77-1.53 ; \mathrm{I}^{2}=\mathrm{N} / \mathrm{A}\right)\right]$, quetiapine $[\mathrm{ES}=1.05(95 \% \mathrm{CI}$ $\left.\left.0.82-1.28 ; \mathrm{I}^{2}=\mathrm{N} / \mathrm{A}\right)\right]$ and olanzapine $[\mathrm{ES}=0.98(95 \%$ CI $\left.0.22-1.73 ; \mathrm{I}^{2}=\mathrm{N} / \mathrm{A}\right)$ ]. In the other NMA mentioned above, the estimated $\mathrm{ES}=0.50$ (95\% CI $0.31-0.67$; $\left.\mathrm{p}<0.001 ; \mathrm{I}^{2}=99 \%\right)$ for aripiprazole and $\mathrm{ES}=0.18(95 \%$ CI $0.10-0.26 ; \mathrm{p}<0.001 ; \mathrm{I}^{2}=99 \%$ ) for brexpiprazole. ${ }^{28}$ Based on another systematic review and meta-analysis, evidence on the use of aripiprazole and quetiapine, as augmentation therapy in TRD patients, was considered the most robust among various treatment options. ${ }^{38}$

\section{Expert Recommendations}

Given the potential side effects and the need for frequent monitoring of lithium, we recommend the use of secondgeneration antipsychotics as the preferred augmentation treatment in TRD patients.

\section{Question 3: TRD Pharmacotherapy - Emerging Evidence? Survey Results}

In Table 3, physicians ranked their most important approach in managing TRD. Most (34\%) physicians ranked "switching to another antidepressant of a different class" as their most important approach; followed by $19 \%$ and $16 \%$ that regarded augmentation with an antipsychotic

Table 3 Number and Percentage of Respondents Ranking the Following Options as Their Most Important Approach for Managing TRD

\begin{tabular}{|l|l|}
\hline Ranking of TRD Treatment Approaches & n (\%) \\
\hline Switch to another antidepressant (different class) & $84(34.1)$ \\
Add antipsychotics & $46(18.7)$ \\
Add another antidepressant & $40(16.3)$ \\
Provide counselling & $27(11.0)$ \\
Conduct electroconvulsive therapy (ECT) & $21(8.5)$ \\
Switch to another antidepressant (same class) & $15(6.1)$ \\
Prolong duration of current therapy & $9(3.7)$ \\
Add other type(s) of drug(s) & $2(0.8)$ \\
Others & $2(0.8)$ \\
\hline
\end{tabular}

Abbreviations: SD, standard deviation; TRD, treatment-resistant depression. 
or adding another antidepressant, respectively, as the most important. A smaller proportion of physicians regarded counselling (11\%) and ECT (9\%) as most important.

\section{Discussion}

Around $75 \%$ of the physicians ranked pharmacotherapy as their most important approach for the treatment of TRD, with the top three most essential treatments being switching to a different class of antidepressants, add-on therapy with an antipsychotic or another antidepressant. This is consistent with the results from Table 1, where the three most commonly used approaches to treat TRD were augmentation with antipsychotics (32\%), antidepressant monotherapy (29\%), and combination therapy (23\%). Given the importance of pharmacotherapy in managing TRD, it is worthwhile discussing briefly two emerging pharmacotherapies that have yet to attain regulatory approval for the treatment of TRD in Asia.

\section{Esketamine}

The United States Food and Drug Administration (US FDA) and, more recently, the European Medicine Agency (EMA) has approved esketamine nasal spray for use in adults with TRD. ${ }^{39-41}$ The FDA also provided their rationale for approving esketamine, with a Risk Evaluation and Mitigation Strategy (REMS), based on "substantial evidence of effectiveness". ${ }^{42}$ The US REMS requires esketamine to be dispensed and administered under the direct observation of a healthcare provider in healthcare settings. The boxed warning of esketamine's US prescribing information states

because of the risks of sedation and dissociation, patients must be monitored for at least 2 hours at each treatment session, followed by an assessment to determine when the patient is considered clinically stable and ready to leave the healthcare setting.

Esketamine can also cause transient increase in blood pressure or decline in cognitive performance requiring the 2-hour monitoring. ${ }^{41}$ Indication statements may differ between regulatory agencies, but the therapeutic indications for Spravato ${ }^{\circledR}$ Summary of Product Characteristics from the EMA states

Spravato $^{\circledR}$, in combination with a SSRI or SNRI, is indicated for adults with treatment-resistant Major Depressive Disorder, who have not responded to at least two different treatments with antidepressants in the current moderate to severe depressive episode. ${ }^{40}$
Esketamine was studied in a robust Phase 3 clinical trial program with more than 1700 adults with TRD. $^{39}$ In a short-term (4-week) study, adult TRD patients treated with esketamine plus a newly initiated oral antidepressant was statistically superior [mean difference -4.0 (95\% confidence interval (CI): -7.3 to -0.6$)$ ] compared to placebo plus newly initiated antidepressant in the change in MADRS total score at Week 4 versus baseline. ${ }^{43,44}$ Esketamine also demonstrated effectiveness in delaying and reducing the risk of relapse in a separate long-term study that is discussed in more detail below. ${ }^{45}$

\section{Ketamine}

Ketamine is currently being used off-label in the United States for various mood and other psychiatric disorders, including TRD. ${ }^{46}$ However, studies supporting the efficacy of ketamine in TRD are generally limited by their small sample sizes. There is also a general lack of safety and longterm efficacy data. ${ }^{47,48}$ In addition, abuse of ketamine has been observed in some parts of Asia, including Hong Kong, Mainland China, and Taiwan. ${ }^{49}$ As such, ketamine is scheduled as a controlled substance in several countries across Asia and is currently not indicated for the treatment of TRD. ${ }^{50-52}$ More information on ketamine use is available from a consensus statement developed by the American Psychiatric Association (APA) Council of Research Task Force on Novel Biomarkers and Treatments. ${ }^{46}$

\section{Expert Recommendations}

In addition to conventional approaches, physicians may consider the use of emerging therapies (eg, esketamine) when these attain approval for TRD treatment and are made available in their countries.

\section{Question 4: TRD Pharmacotherapy - Target Treatment Duration? Survey Results}

Survey participants were asked how long they would continue to treat a TRD patient with inadequate response to his/ her current antidepressant before changing the treatment. Around $30 \%$ of the Asian physicians indicated 4 to $<6$ weeks, while $25 \%$ would treat for 6 to $<8$ weeks (Table 4 ). A minority of the physicians (17\%) would make a treatment change within 4 weeks.

\section{Discussion}

This discussion focuses on two clinical scenarios during TRD treatment: firstly, when the current antidepressant 
Table 4 Duration of Antidepressant Treatment Trial in TRD Patients

\begin{tabular}{|l|l|}
\hline Antidepressant Treatment Trial in TRD Patients & $\mathbf{n ~ ( \% )}$ \\
\hline$<4$ weeks & $39(17.1)$ \\
4 to $<6$ weeks & $69(30.3)$ \\
6 to $<8$ weeks & $57(25.0)$ \\
8 to $<10$ weeks & $22(9.6)$ \\
10 to $<12$ weeks & $23(10.1)$ \\
$\geq 12$ weeks & $13(5.7)$ \\
Others & $5(2.2)$ \\
\hline
\end{tabular}

Abbreviation: TRD, treatment-resistant depression.

fails; and secondly, when the patient responds or achieves remission with the current antidepressant.

\section{Treatment Failure}

In a separate publication currently under review, the expert panel recommended a time frame of 6-8 weeks for an adequate antidepressant treatment trial prior to diagnosing TRD (Han et al, Definition and identification of patients with treatment-resistant depression in real-world clinical practice settings across Asia). This survey question was aimed at understanding whether Asian physicians think differently of this time frame before and after the diagnosis of TRD. Prior to TRD diagnosis, $17.9 \%, 34.3 \%, 23.7 \%$, $7.6 \%$, and $8.9 \%$ of Asian physicians indicated the appropriate time frame to be $<4$ weeks, 4 to $<6$ weeks, 6 to $<8$ weeks, 8 to $<10$ weeks and 10 to $<12$ weeks, respectively (Han et al, Definition and identification of patients with treatment-resistant depression in real-world clinical practice settings across Asia). The current results appear to show a marginal increase in the number of Asian physicians indicating a longer time frame $(9.6 \%$ for 8 to $<10$ weeks and $10.1 \%$ for 10 to $<12$ weeks) after TRD diagnosis compared to before diagnosis. In contrast, a study using commercial claims in the United States found that the duration of lines of therapy (LOT) of antidepressants among TRD episodes were shorter than the corresponding LOT in non-TRD episodes. ${ }^{53}$ The study did not capture the reasons for changing treatment after each LOT, but the authors suggested a pattern of inadequate response to previous LOT in TRD episodes may have triggered physicians to make treatment changes more readily when encountering a lack of response with the current LOT. There is currently no evidence to suggest any benefit with adjusting the duration of antidepressant treatment trials post-diagnosis of TRD versus pre-diagnosis.

\section{Treatment Response or Remission}

For this section, we shall explore treatment continuation to achieve and preserve remission, prevent relapses and recurrences, and to eventually attain recovery. Several meta-analyses and reviews have demonstrated the benefits (prevention of relapse/recurrence) of continued longertermed use of antidepressants versus discontinuation for MDD patients who have responded to acute treatment. ${ }^{54-56}$ In the esketamine long-term study, continued use of esketamine in TRD patients resulted in a statistically significant delay in time to relapse, with a 51\% [hazard ratio (HR) 0.49 (95\% CI: $0.29,0.84)$ ] and $70 \%$ [HR $0.30(95 \% \mathrm{CI}: 0.16,0.55)$ ] relative risk reduction in relapse versus placebo (ie, esketamine discontinuation), among stable remitters and stable responders, respectively. ${ }^{39}$

In the same trial, the proportion of stable remitters (45\%) maintained on placebo (ie, discontinued esketamine), who relapsed was lower compared to stable responders $(58 \%)$ on placebo. ${ }^{57}$ One may view stable responders here as an enriched population, with even more treatmentresistant TRD patients, who were not able to achieve the more stringent treatment goal of remission. Hence, it is not surprising for stable responders to achieve a larger treatment effect (HR 0.30) with esketamine, and a higher relapse rate $(58 \%)$ with esketamine discontinuation when compared to the stable remitters (HR 0.49 and 45\%, respectively). Based on this argument, TRD patients may benefit even more from long-term treatment compared to non-TRD patients.

The APA guidelines recommend patients with depressive disorders, who have been successfully treated with antidepressants in the acute phase, to continue treatment with these agents for another 4 to 9 months to reduce the risk of relapse. ${ }^{23}$ Continuing treatment for at least another 6 months after patients achieve remission to reduce the risk of relapse is consistent with recommendations from various guidelines. $^{14,16,23,58,59}$

A question commonly encountered by physicians from patients is "when can I stop treatment?". Data from a pooled analysis, including 31 randomized trials that recruited 4410 patients with depressive disorders who have responded to acute treatment, demonstrated a $70 \%$ reduction in the odds of relapse in patients continuing treatment (relapse rate 18\%) with antidepressants compared to treatment discontinuation (relapse rate $41 \%$ ). ${ }^{56}$ Although most trials lasted for a duration of 12 months, the treatment effect was observed to persist for up to 36 
months in other included studies. There is little data comparing different lengths of maintenance treatment with active medication. ${ }^{58}$ Hence, most guidelines can only recommend, non-definitively, a treatment period of between 1 and 3 years. ${ }^{58,59}$ Consistent with a previously published expert consensus guideline, ${ }^{2}$ a more recent review on the management of depression, albeit in older adults, recommended assessing patients a year after achieving remission for potential discontinuation of antidepressants: consider tapering off antidepressant gradually in patients with a single (ie, current) episode of depression; consider continuing antidepressant for another $\geq 1$ years (total treatment duration $\geq 2$ years) in patients with two episodes of depression; consider continuing antidepressant for another $\geq 2$ years (total treatment duration $\geq 3$ years and perhaps indefinitely) in patients with three or more depressive episodes. $^{60,61}$

\section{Expert Recommendations}

The time frame for an adequate antidepressant treatment trial should remain consistent at 6-8 weeks before and even after a diagnosis of TRD has been made. In line with the recommendations from current clinical practice guidelines, patients achieving remission with acute treatment should continue their antidepressants for another at least 6 months to prevent relapse/recurrence. Patients should be followed up regularly to determine the need for further antidepressant maintenance therapy beyond 6 months, based on their risks of relapse/recurrence, presence of residual symptoms, severity and chronicity of episode, safety/tolerability to their current antidepressants, psychosocial function, comorbidities, and preferences. ${ }^{23}$

\section{Question 5: TRD Somatic Treatment - Role of ECT? Survey Results}

Quantitative Responses: Only 9\% of the physicians indicated ECT as the most important treatment for TRD (Table 3). Participants generally considered using ECT in combination with pharmacotherapy for TRD patients (Tables 1 and 2).

Qualitative Themes: Physicians were asked under what clinical scenarios/circumstances they would consider using ECT and the frequency of ECT use."Severity of symptoms" emerged as a salient theme raised among physicians who used ECT. Some mentioned prescribing ECT for TRD patients who are "highly treatment-resistant", "unresponsive" and/or demonstrate "poor tolerability to pharmacotherapy", at "high risk of relapse/recurrence", display "catatonic symptoms" and/or "food refusal". ECT was also considered useful when a "quick response is needed"; for example, in patients with "suicidal ideation or behavior". Most Asian physicians used ECT for $<5$ patients per year. A few used ECT for $\geq 10$ patients per year. Only one physician cited about 30 patients per year. Of the physicians who did not routinely use ECT, most of them did not recommend its use; with the rest endorsing ECT but had “limited access". Physicians' concerns related to ECT use included "difficulty in obtaining patient/family consent" (for "hospitalization" and/or "anesthesia") as well as postECT “cognitive impairment" and "(patient) psychological trauma".

\section{Discussion}

The safety and effectiveness of ECT for depression has been well-established since $1941 .^{62,63}$ However, access to ECT remains a challenge for many countries, including those in Asia. A systematic review showed that globally, under half of all psychiatric institutions within the same country provided ECT. ${ }^{62}$ Survey results of 334 psychiatric facilities across 29 Asian countries revealed that ECT was available only in 257 institutions (77\%) across 23 countries $(79 \%)$. Around $42 \%$ of ECT conducted was for schizophrenia and $32 \%$ for MDD. ${ }^{64}$ The World Health Organization (WHO) recommends that ECT should only be administered with anesthesia and muscle relaxation. ${ }^{65}$ The lack of access to anesthesia and anesthesiologists in some countries further aggravates the limited availability of ECT. ${ }^{62}$ It is not surprising then that only $3 \%$ and $9 \%$ of the surveyed physicians used antidepressant-ECT combination (Table 1) and ranked ECT as the most important approach (Table 3), respectively, for the treatment of TRD. Despite these limitations, in-line with the APA guidelines, the National Institute for Health and Care Excellence (NICE), and the Canadian Network for Mood and Anxiety Treatments (CANMAT) guidelines, ECT remains an important treatment option for depression in various clinical scenarios, including severe depressive episodes and medication treatment failures. ${ }^{23,59,66-69}$

\section{Severe Depressive Episode Needing Rapid Response}

Given its faster response (with relief of depressive symptoms within 10-14 days) compared to current pharmacotherapy available in Asia, ECT is indicated as the firstline treatment for severe depressive episode (MADRS $>34$, HAMD-17 $\geq 24$ or Patient Health Questionnaire (PHQ)-9 $\geq 20$ ) with high suicidality, acute danger of self- 
harm and/or harm to others, psychotic symptoms, depressive stupor and/or severe reduction in oral intake. ${ }^{14,67,69-72}$ It may be worthwhile noting here that the treatment difference (change in MADRS total score at Week 4 versus baseline) between the esketamine and placebo groups was observed within 24 hours and generally remained through Day 28 in a short-term (4-week) study. The mean baseline MADRS score was 37.0 and 37.3 in the esketamine and placebo treatment arms, respectively. ${ }^{39}$

\section{Medication Treatment Failures Needing Greater Efficacy} Superiority of ECT compared to antidepressants has been well-established through RCTs and meta-analyses. ${ }^{73-75}$ However, the use of ECT is not without its concerns. Although ECT is considered one of the safest medical procedures under anesthesia, it can result in troubling somatic (eg, headache, nausea, and vomiting) and cognitive side effects (eg, confusion, memory disturbances, and attention deficits). ${ }^{69}$ In addition to the issues with access discussed above, the relatively invasive nature of ECT may also impact patient/caregiver preferences, and the cost of ECT may be prohibitive for patients in some Asian countries. Hence, ECT is only indicated as a secondline treatment for medication treatment failures in depression. $^{67,69}$

TMS was mentioned as part of the "others" option in Table 1. Several meta-analyses comparing TMS to sham treatment support the use of TMS in MDD patients who have failed $\geq 1$ antidepressant treatment trial. ${ }^{76-78}$ This is consistent with the recommendations from the various treatment guidelines and expert consensus. ${ }^{67,79}$ Most clinical trials comparing TMS versus sham treatment involve TMS being added onto antidepressants. Fewer studies compared antidepressant-free TMS with sham treatment. $^{79,80}$ Overall, evidence points to ECT being more efficacious than TMS. ${ }^{80-82}$ There is limited data comparing TMS head-to-head with pharmacotherapy. In addition to ECT and TMS, there is also some early data on the use of vagus nerve stimulation (VNS) and deep brain stimulation (DBS) for the treatment of TRD, albeit nonconclusive. $^{83}$

\section{Expert Recommendations}

Similar to the recommendations from current clinical treatment guidelines, for TRD patients with severe symptoms requiring urgent relief, ECT is the treatment of choice given its efficacy, safety, and rapidity of response. Esketamine can be a potential treatment option for such patients once it is approved and made available for use. ECT and TMS can be considered, with a preference for ECT given its superior efficacy, for TRD patients who remain symptomatic despite multiple adequate trials of antidepressants. The choice of therapy should be made with due consideration for patient/caregiver preference, cost, and accessibility of such treatments. Though ECT with anesthesia is not readily available in some Asian countries, its implementation would expand the treatment options for this patient population with difficult-to-treat depression.

\section{Question 6: TRD Treatment - Role of Psychotherapy? Survey Results}

Quantitative Responses: Around 11\% of surveyed physicians indicated "counseling" as the most important TRD treatment approach (Table 3).

Qualitative Themes: There was no consistent theme regarding when physicians would initiate psychotherapy. Some would start psychotherapy once patients are "mentally stable", while others would consider psychotherapy after varying numbers of "antidepressant failures". Almost all physicians provided some form of "psychotherapy in combination with pharmacotherapy". Some physicians were more specific regarding the type of psychotherapy they provided, mentioning "cognitive behavioral therapy (CBT)", "interpersonal therapy (IPT)" or "psychodynamic therapy". A number of physicians did not routinely offer psychotherapy due to a "lack of time and/or resources". Some of these physicians may provide "general counseling" as an alternative.

\section{Discussion}

Multiple studies and meta-analyses seem to suggest a combination of psychotherapy with pharmacotherapy as being more effective than psychotherapy or pharmacotherapy alone. ${ }^{84-86}$ This finding is consistent with the guidelines from the APA, NICE, CANMAT, and World Federation of Societies of Biological Psychiatry (WFSBP), which recommend combining psychotherapy with antidepressants for the treatment of patients with depressive disorders. ${ }^{16,23,66,67,87}$ A recent systematic review and meta-analysis assessed the effectiveness, expressed as effect size (ES), of psychological and pharmacological augmentation interventions for TRD. ${ }^{29}$ Psychological therapies [ES $=1.43$ (95\% CI 0.50-2.36, $\left.\left.\mathrm{I}^{2}=95.3 \%\right)\right]$ and pharmacological augmentation 
treatments $\left[\mathrm{ES}=1.19\left(95 \%\right.\right.$ CI $\left.1.08-1.30, \mathrm{I}^{2}=64.6 \%\right)$ ] yielded similar effects. These effect sizes appeared larger than psychological placebo [ES $=0.94(95 \%$ CI $0.36-1.52$, $\left.\left.\mathrm{I}^{2}=89.1 \%\right)\right]$ and pill placebo $[\mathrm{ES}=0.78(95 \%$ CI $0.66--$ $\left.\left.0.91, \mathrm{I}^{2}=68.8 \%\right)\right]$, respectively. However, interpretation of results was made somewhat difficult because of overlapping confidence intervals and significant statistical heterogeneity, defined as $\mathrm{I}^{2}>60 \%$. Of note, among the 28 trials that met the inclusion criteria of this TRD systematic review and meta-analysis, only 3 trials investigated psychological treatments compared with 25 examining pharmacological interventions. This may bear some semblance with the general limited body of evidence that is available on psychological therapies in TRD. There is no compelling data, especially in TRD patients, to suggest one type of psychotherapy (CBT, IPT, etc.) as being superior to another. There is also no data comparing the effectiveness of different antidepressant-psychotherapy combinations.

\section{Expert Recommendations}

According to current clinical practice guidelines, physicians are strongly encouraged to optimize psychological and psychosocial interventions when treating all patients with TRD. The choice of the type of psychotherapy needs to take into account its availability and patient preferences.

\section{Question 7: Use of TRD Treatment Guidelines? Survey Results}

Survey participants were first asked about their awareness of TRD-specific guidelines (ie, Yes or No). About $76 \%$ $(n=187)$ of the surveyed physicians claimed they were aware of guidelines with TRD-specific recommendations (Figure 1). The 187 physicians who responded "yes" were then asked which TRD-specific guidelines they were aware of (selecting all that applied) based off a list described in Supplement 2. There was also an option to name guidelines that were not included in this list under "others (please specify)". For this question, $80 \%$ and $60 \%$ of surveyed physicians were aware of the APA and NICE guidelines, respectively.

Next, the same 187 physicians were asked if they followed guidelines when managing TRD and, if so, indicate these guidelines by selecting all that applied from a list described in Supplement 2. Once again, these surveyed physicians could name guidelines that were not mentioned in this list under "others (please specify)". Around $81 \%(n=152)$ of them followed guidelines when managing TRD patients (Figure 2). Among those who followed guidelines, $55 \%$ of them followed the APA guidelines, while $41 \%$ followed the NICE and WFSBP guidelines.

\section{Discussion}

A large proportion of surveyed physicians were aware of guidelines with TRD-specific recommendations. Among these, a large majority (81\%) followed the guidelines when managing their TRD patients. Guidelines from the APA, NICE, and WFSBP were the top three guidelines Asian physicians followed.

A recent systematic review did not reveal any guidelines developed specifically for $\mathrm{TRD}^{2}$ but in 2019 , the French Association for Biological Psychiatry and Neuropsychopharmacology published "Clinical guidelines for the management of treatment-resistant depression". ${ }^{88}$ In addition, some MDD guidelines do contain recommendations for TRD diagnosis and treatment. ${ }^{58,59,67}$

\section{Expert Recommendations}

TRD-specific guidelines are currently limited. Professional Psychiatry Associations should consider developing TRDspecific clinical practice guidelines to address the significant ambiguity related to TRD diagnosis and treatment.

\section{Question 8: Challenges in Managing TRD? Survey Results}

Quantitative Responses: Survey participants were asked if they were satisfied with the currently available treatment options for TRD. Only $60 \%(n=147)$ of Asian physicians were satisfied with the current TRD treatment options. Surveyed physicians were also asked to rank their top three challenges faced when diagnosing and managing TRD patients based off the list provided in Table 5 . Surveyed physicians had the option of describing and ranking challenges that were not included in the list under "others (please specify)". Table 5 describes the proportion of surveyed physicians who ranked the various challenges as their top challenge when diagnosing and managing TRD patients. For diagnosis, 38\% identified their biggest challenge as related to a deficient TRD definition; $20 \%$ cited treatment discontinuation and loss to follow-up; and $14 \%$ were related to a lack of guidelines. For the management of TRD, treatment discontinuation and loss to follow-up was the top challenge (41\%). Another $15 \%$ of the physicians indicated a lack of therapeutic options as their biggest challenge; $14 \%$ and $13 \%$ 


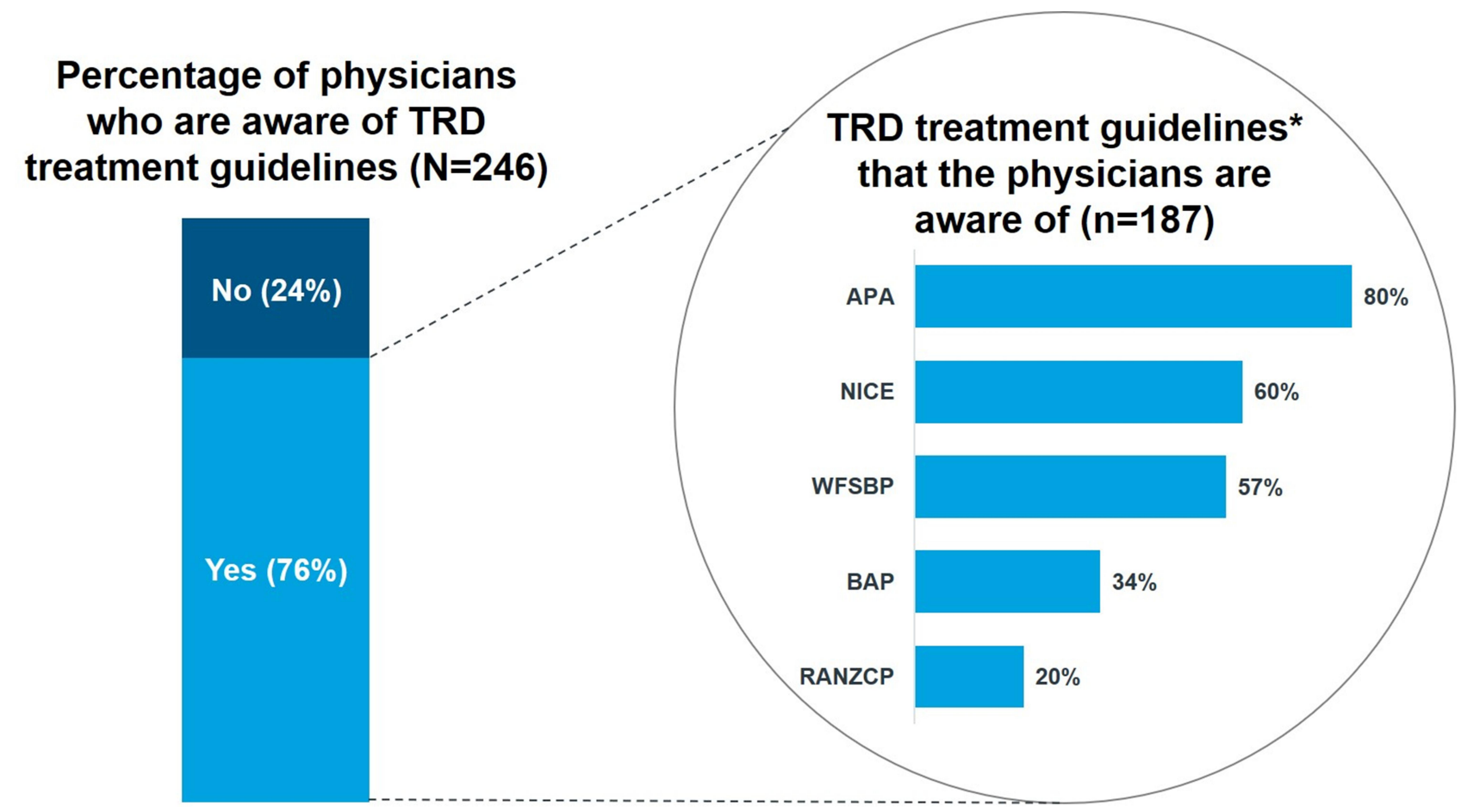

Figure I Awareness of Guidelines with TRD-specific Recommendations.

Note: *Other guidelines include the American Academy of Family Physicians (AAFP) guidelines (5\%), the CANMAT guidelines (2\%), and local guidelines (4\%).

Abbreviations: APA, American Psychiatric Association; BAP, British Association for Psychopharmacology; NICE, National Institute for Health and Care Excellence; RANZCP, Royal Australian and New Zealand College of Psychiatrists; TRD, treatment-resistant depression; WFSBP, World Federation of Societies of Biological Psychiatry.

were related to a lack of a standardized TRD definition and a lack of TRD-specific guidelines, respectively.

Qualitative Themes: The two salient themes identified in relation to the challenges with TRD management were "inadequacy of current treatment options" and "its repercussions". Many physicians were frustrated with the current treatment options because of a "lack of efficacy" and an "inability to stop disease progression", with one participant describing it as having "no way to ease it (ie, the TRD condition) despite the maximum dose of different treatments". The "repercussions" of lacking adequate TRD treatment options included "poor outcomes", patientphysician "trust is broken" with a "loss of confidence" in the treatment plan. Many patients end up "doctor/clinic/ hospital-hopping", as recounted by one participant.

\section{Discussion}

A survey of 784 physicians from the United States, France, Germany, Italy, Spain, and the United Kingdom found that $62 \%$ of physicians were dissatisfied with the management of their TRD patients. ${ }^{89}$ Our survey showed a slightly smaller proportion of Asian physicians (40\%) being dissatisfied with the current treatment options for TRD. The challenges facing the diagnosis and management of TRD appear to revolve around three key themes: firstly, a lack of standardized guidance on the definition, diagnosis (patient identification) and treatment of TRD; secondly, a lack of effective treatment options for TRD; and finally, poor treatment adherence and loss to follow-up.

\section{Expert Recommendations}

Evidence generation is critically needed to address significant data gaps related to the diagnosis and treatment of TRD. Development and education on TRD-specific guidance is also strongly encouraged. In addition, more effort is needed to conduct research into new treatment options for TRD that are evidence-based.

\section{Strengths and Limitations}

There is limited ability to generalize the results of this survey to the medical community across the entire Asia region due to the involvement of only five major Asian countries. Inherent to the nature of questionnaires, surveyed respondents may occasionally provide "right (what they should be doing)" rather than "real (what they are actually doing)" answers. Survey responses to open-ended questions can be subjective and open to interpretation. Design of the survey, including how the questions were 


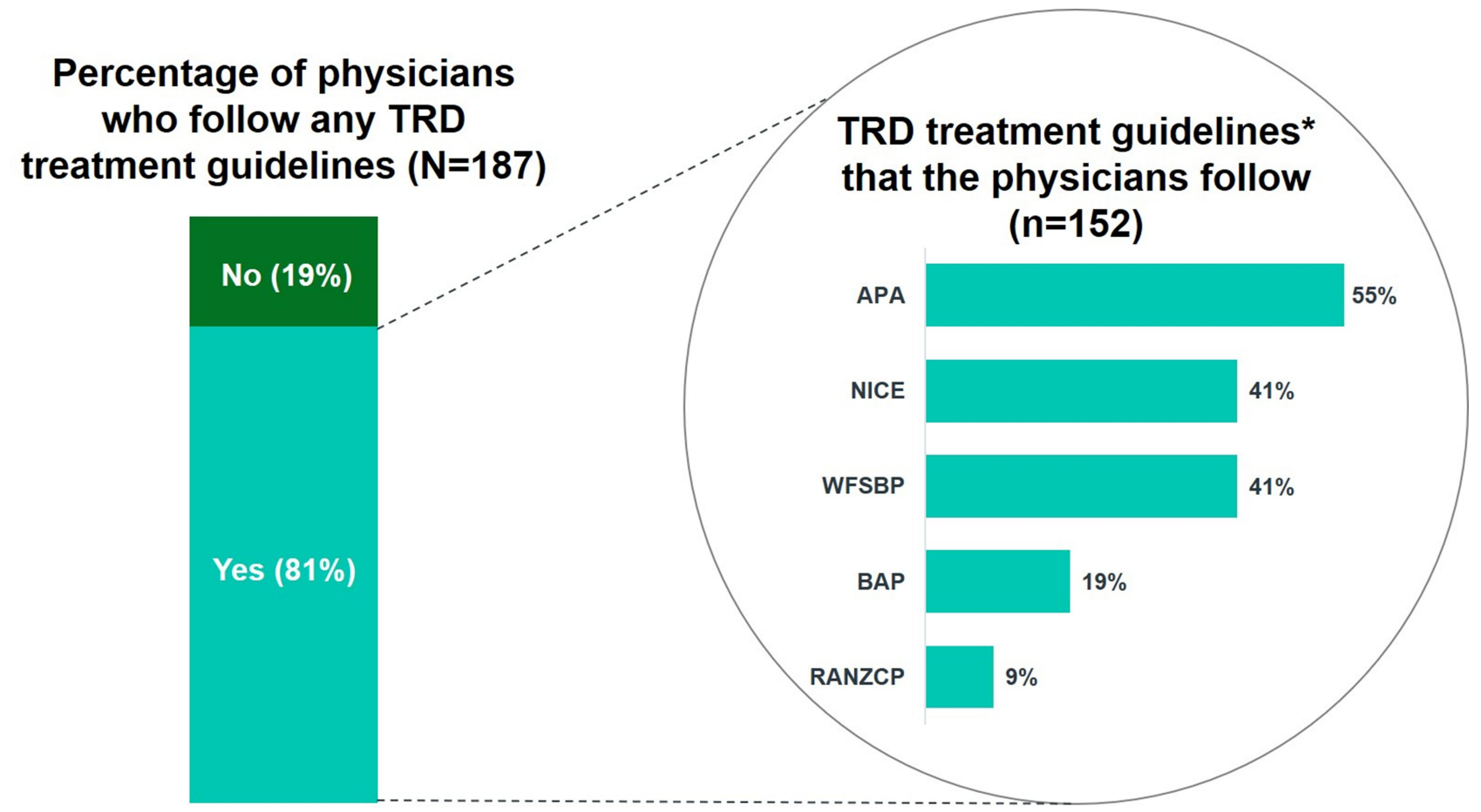

Figure 2 Following Treatment Guidelines for TRD Management.

Note: *Other guidelines include the American Academy of Family Physicians (AAFP) guidelines (1\%), the CANMAT guidelines (2\%), and local guidelines (4\%).

Abbreviations: APA, American Psychiatric Association; BAP, British Association for Psychopharmacology; NICE, National Institute for Health and Care Excellence; RANZCP, Royal Australian and New Zealand College of Psychiatrists; TRD, treatment-resistant depression; WFSBP, World Federation of Societies of Biological Psychiatry.

being asked, could also have influenced the physicians' responses. As the aim of this survey was to explore the TRD treatment pattern across Asia, many questions were focused on the physicians' prescribing behavior, and did not probe further into the rationale for those responses that can be influenced by the role of the surveyed physician, types of patients seen, local healthcare settings and local "treatment culture".

To our knowledge, this is the first survey that recruited physicians across several Asian countries from various practice types (eg, public vs private) to understand the management of TRD across Asia. Given the lack of consensus and specific guidance on TRD management, it is useful to understand how Asian physicians are treating TRD patients in their day-to-day clinical practice in order to identify potential educational and evidence gaps.

\section{Conclusion}

In the management of TRD, polytherapy (71\%) was used more frequently than monotherapy (29\%) among Asian physicians; with antipsychotic augmentation being the most common (23\%). Around $34 \%$ of physicians deemed switching to another class of antidepressants as their most important TRD treatment approach, while a smaller proportion chose antidepressant combination therapy $(16 \%)$ and ECT (9\%), respectively. Although most physicians acknowledged the benefits of combining psychotherapy with pharmacotherapy, some physicians did not routinely offer psychotherapy because of a lack of time and/or access to psychotherapy.

Based on the survey results, TRD patients who responded partially to antidepressants can be considered for augmentation with second-generation antipsychotics, while switching to another class of antidepressants can be considered for nonresponders, especially after two or more antidepressant failures from the same class. TRD patients achieving remission with acute treatment should be considered for continuing their antidepressants for at least another 6 months to prevent relapse/recurrence. Thereafter, patients should be followed up regularly to determine the need for further antidepressant maintenance therapy beyond 6 months. ECT can be considered for TRD patients with severe depression and/or persistent symptoms despite multiple adequate trials of antidepressants. Improving access to ECT across Asia can help expand the treatment options for this difficult-to-treat patient population. Psychotherapy should be provided in combination with pharmacotherapy to all patients to achieve better treatment outcomes. 
Table 5 Top Challenges Faced by Asia Physicians in Diagnosing and Managing TRD

\begin{tabular}{|c|c|}
\hline Challenges in TRD Diagnosis & $\%$ \\
\hline TRD Definition: lack of a clarity in identifying TRD patients (global issue) & 16.7 \\
\hline Patient dropout/lack of follow-up due to failed treatments & 15.0 \\
\hline TRD Definition: lack of a clarity in identifying TRD patients (in my country) & 14.2 \\
\hline Cultural and social stigma for reporting non-responsiveness to treatment & 8.1 \\
\hline Lack of adequate (local) guidelines for managing TRD patients & 7.7 \\
\hline Gap between ideal versus practical TRD definition & 7.3 \\
\hline Lack of adequate (global) guidelines for managing TRD patients & 6.1 \\
\hline Heterogeneity of MDD/TRD patients & 5.3 \\
\hline Lack of TRD therapeutic options & 4.9 \\
\hline Presence of comorbidities & 4.9 \\
\hline Patients do not adhere to treatment and follow-up visit & 4.5 \\
\hline Physicians are not proactive in diagnosing TRD & 4.1 \\
\hline Patients cannot afford the treatment for TRD & 0.0 \\
\hline Others & 1.2 \\
\hline Challenges in Managing TRD & $\%$ \\
\hline Patient dropout/lack of follow-up due to failed treatments & 27.2 \\
\hline Lack of TRD therapeutic options & 14.6 \\
\hline Patients do not adhere to treatment and follow-up visit & 14.2 \\
\hline Lack of adequate (global) guidelines for managing TRD patients & 6.5 \\
\hline Lack of adequate (local) guidelines for managing TRD patients & 6.5 \\
\hline TRD Definition: lack of a clarity in identifying TRD patients (global issue) & 5.7 \\
\hline TRD Definition: lack of a clarity in identifying TRD patients (in my country) & 4.9 \\
\hline Cultural and social stigma for reporting non-responsiveness to treatment & 4.9 \\
\hline Presence of comorbidities & 4.5 \\
\hline Heterogeneity of MDD/TRD patients & 4.1 \\
\hline Gap between ideal versus practical TRD definition clinical practice & 3.3 \\
\hline Physicians are not proactive in diagnosing TRD & 1.6 \\
\hline Patients cannot afford the treatment for TRD & 1.2 \\
\hline Others & 0.8 \\
\hline
\end{tabular}

Abbreviations: MDD, major depressive disorder; TRD, treatment-resistant depression.

\section{Acknowledgment}

The article comprised of 2 parts: Firstly, a cross-sectional survey was conducted to describe how TRD was being diagnosed and managed by Asian physicians in the real-world setting. Secondly, an expert panel was convened to interpret the survey results and provide practical recommendations. We confirm informed consent was obtained from participants in both the survey and the expert panel. We further confirm the cross-sectional survey complied with the Declaration of Helsinki. We thank IQVIA Asia-Pacific for collecting the data and conducting the statistical analysis. Janssen Pharmaceuticals Asia-Pacific conceived and conceptualized the study design, while data collection was conducted by IQVIA Asia-Pacific.

\section{Author Contributions}

All authors made substantial contributions to analysis and interpretation of data; took part in drafting the article or revising it critically for important intellectual content; agreed on the journal to which the article will be submitted; gave final approval of the version to be published; and agree to be accountable for all aspects of the work.

\section{Funding}

Janssen Pharmaceuticals Asia-Pacific provided funding for the data collection.

\section{Disclosure}

Chee $\mathrm{H} \mathrm{Ng}$ had served as an advisory committee member for Lundbeck, Grunbiotics, Servier, Pfizer and Eli Lilly, received research grant support from Wyeth, Pfizer and Lundbeck, and speaker honoraria from Janssen AsiaPacific, Servier, Lundbeck, Bristol-Myers Squibb, Organon, Eli Lilly, GlaxoSmithKline, Janssen-Cilag, AstraZeneca, Wyeth and Pfizer. Chia-Yih Liu served on advisory boards for Eli Lilly, Janssen, Pfizer, GlaxoSmithKline, and Servier; and received grant/research support from Eli Lilly, 
Janssen, Otsuka, Sumitomo and Sanofi-Aventis; received grants from Ministry of Science and Technology, ROC (Taiwan) and Chang Gung Medical Foundation, outside the submitted work; is a member of the speakers' bureaus for AstraZeneca, Eli Lilly, GlaxoSmithKline, Janssen, Otsuka, Pfizer, Sanofi-Aventis, and Servier. Changsu Han is a member of speakers' bureaus for Lundbeck, Otsuka, Lilly Korea, Pfizer Korea, Janssen Korea; and received research support from the department of public health \& welfare of South Korea, Otsuka Korea, Eisai, and AB Biotics. Gang Wang reports receiving grants outside of the submitted work from Chiatai Tianqing, Dainippon Sumitomo Pharma, Eli Lilly, GlaxoSmithKline, Jiangsu Hansoh, Otsuka Pharmaceutical, Shandong Luye, Shijiazhuang No 4 Pharm, and Xi'an Janssen. Tadafumi Kato reports receiving personal fees outside of the submitted work from Agilent Technologies, Astellas, Boehringer Ingelheim, Dainippon Sumitomo Pharma Co., Ltd., Eli Lilly, Nippon Boehringer Ingelheim Co. Ltd., GlaxoSmithKline, Janssen, Kyowa Hakko Kirin Co., Ltd, Kyowa Pharmaceutical Industry Co., Ltd, Meiji Seika Pharma Co., Ltd., Mochida Pharmaceutical Co., Ltd., MSD, Otsuka Pharmaceutical Co., Ltd., Pfizer, Shionogi \& Co., Ltd., Taisho Pharma Co., Ltd, Taisho Toyama Pharmaceutical Co., Ltd., Wako Pure Chemical Industries, and Yoshitomi Yakuhin. He also reports grants and personal fees from Takeda outside of the submitted work. Lili Zhang, Wilson Tan, and Yu Feng are employees of Janssen AsiaPacific. Wilson Tan holds shares in Janssen Asia-Pacific awarded as part of his total compensation package. The authors report no other conflicts of interest associated with this work.

\section{References}

1. Nierenberg AA, Amsterdam JD. Treatment-resistant depression: definition and treatment approaches. J Clin Psychiatry. 1990;51(Suppl):39-50.

2. $\mathrm{Ng} \mathrm{CH}$, Kato T, Han C, et al. Definition of treatment-resistant depression - Asia Pacific perspectives. J Affect Disord. 2019;245:626-636. doi:10.1016/j.jad.2018.11.038

3. Ervasti J, Vahtera J, Pentti J, et al. Depression-related work disability: socioeconomic inequalities in onset, duration and recurrence. PLoS One. 2013;8(11):e79855. doi:10.1371/journal.pone.0079855

4. Olchanski N, McInnis Myers M, Halseth M, et al. The economic burden of treatment-resistant depression. Clin Ther. 2013;35 (4):512-522. doi:10.1016/j.clinthera.2012.09.001

5. Mahlich J, Tsukazawa S, Wiegand F. Estimating prevalence and healthcare utilization for treatment-resistant depression in Japan: a retrospective claims database study. Drugs Real World Outcomes. 2018;5(1):35-43. doi:10.1007/s40801-017-0126-5

6. Warden D, Rush AJ, Trivedi MH, Fava M, Wisniewski SR. The STAR*D Project results: a comprehensive review of findings. Curr Psychiatry Rep. 2007;9(6):449-459. doi:10.1007/s11920-007-0061-3
7. Fife D, Feng Y, Wang MY, et al. Epidemiology of pharmaceutically treated depression and treatment resistant depression in Taiwan. Psychiatry Res. 2017;252:277-283. doi:10.1016/j.psychres.20 17.03.006

8. Kim N, Cho SJ, Kim H, et al. Epidemiology of pharmaceutically treated depression and treatment resistant depression in South Korea. PLoS One. 2019;14(8):e0221552. doi:10.1371/journal.pone.0221552

9. Pérez-Wehbe AI, Perestelo-Pérez L, Bethencourt-Pérez JM, CuéllarPompa L, Peñate-Castro W. Treatment-resistant depression: a systematic review of systematic reviews. Int $J$ Clin Health Psychol. 2014;14(2):145-153. doi:10.1016/S1697-2600(14)70048-1

10. McIntyre RS, Filteau MJ, Martin L, et al. Treatment-resistant depression: definitions, review of the evidence, and algorithmic approach. $J$ Affect Disord. 2014;156:1-7. doi:10.1016/j.jad.2013.10.043

11. Thase M, Connolly KR Unipolar depression in adults: treatment of resistant depression; 2015. Available from: https://www.uptodate. com/contents/unipolar-depression-in-adults-choosing-treatment-forresistant-depression. Accessed November 24, 2019.

12. Stata Statistical Software: release 15 [computer program]. College Station, TX: StataCorp LLC; 2017.

13. QSR International. NVivo Qualitative Data Analysis Software. 11th ed. QSR International Pty Ltd.; 2017.

14. Bauer M, Pfennig A, Severus E, Whybrow PC, Angst J, Moller HJ. World Federation of Societies of Biological Psychiatry (WFSBP) guidelines for biological treatment of unipolar depressive disorders, part 1: update 2013 on the acute and continuation treatment of unipolar depressive disorders. World J Biol Psychiatry. 2013;14 (5):334-385.

15. Cleare A, Pariante CM, Young AH, et al. Evidence-based guidelines for treating depressive disorders with antidepressants: a revision of the 2008 British Association for Psychopharmacology guidelines. J Psychopharmacol. 2015;29(5):459-525.

16. National Collaborating Centre for Mental Health. Depression: the treatment and management of depression in adults (updated edition); 2010.

17. Fava M, Davidson KG. Definition and epidemiology of treatment-resistant depression. Psychiatr Clin North Am. 1996;19 (2):179-200. doi:10.1016/S0193-953X(05)70283-5

18. Nierenberg AA, DeCecco LM. Definitions of antidepressant treatment response, remission, nonresponse, partial response, and other relevant outcomes: a focus on treatment-resistant depression. J Clin Psychiatry. 2001;62(Suppl 16):5-9.

19. Liu CY, Yeh TL, Chen CS, et al. Treatment Guideline for Major Depressive Disorder in Primary Care. Taipei: Taiwan Association Against Depression; 2012.

20. Gaynes BN, Dusetzina SB, Ellis AR, et al. Treating depression after initial treatment failure: directly comparing switch and augmenting strategies in STAR*D. $J$ Clin Psychopharmacol. 2012;32 (1):114-119. doi:10.1097/JCP.0b013e31823f705d

21. Han C, Wang SM, Kwak KP, et al. Aripiprazole augmentation versus antidepressant switching for patients with major depressive disorder: a 6-week, randomized, rater-blinded, prospective study. $J$ Psychiatr Res. 2015;66-67:84-94. doi:10.1016/j.jpsychires.2015.04.020

22. Mohamed S, Johnson GR, Chen P, et al. Effect of antidepressant switching vs augmentation on remission among patients with major depressive disorder unresponsive to antidepressant treatment: the VAST-D randomized clinical trial. JAMA Psychiatry. 2017;318 (2):132-145.

23. American Psychiatric Association. Practice guideline for the treatment of patients with major depressive disorder; 2010. Available from: https://psychiatryonline.org/pb/assets/raw/sitewide/practice guidelines/guidelines/mdd.pdf. Accessed November 18, 2019.

24. Papakostas GI, Fava M, Thase ME. Treatment of SSRI-resistant depression: a meta-analysis comparing within- versus across-class switches. Biol Psychiatry. 2008;63(7):699-704. doi:10.1016/j. biopsych.2007.08.010 
25. Ruhe HG, Huyser J, Swinkels JA, Schene AH. Switching antidepressants after a first selective serotonin reuptake inhibitor in major depressive disorder: a systematic review. J Clin Psychiatry. 2006;67 (12):1836-1855. doi:10.4088/JCP.v67n1203

26. Fang Y, Yuan C, Xu Y, et al. A pilot study of the efficacy and safety of paroxetine augmented with risperidone, valproate, buspirone, trazodone, or thyroid hormone in adult Chinese patients with treatment-resistant major depression. J Clin Psychopharmacol. 2011;31(5):638-642.

27. Bauer M, Dell'osso L, Kasper S, et al. Extended-release quetiapine fumarate (quetiapine XR) monotherapy and quetiapine XR or lithium as add-on to antidepressants in patients with treatment-resistant major depressive disorder. $J$ Affect Disord. 2013;151(1):209-219. doi:10.1016/j.jad.2013.05.079

28. Carter B, Strawbridge R, Husain MI, et al. Relative effectiveness of augmentation treatments for treatment-resistant depression: a systematic review and network meta-analysis. Int Rev Psychiatry. 2020;32(5-6):477-490. doi:10.1080/09540261.2020.1765748

29. Strawbridge R, Carter B, Marwood L, et al. Augmentation therapies for treatment-resistant depression: systematic review and meta-analysis. Br J Psychiatry. 2019;214(1):42-51. doi:10.1192/ bjp. 2018.233

30. Bauer M, Dopfmer S. Lithium augmentation in treatment-resistant depression: meta-analysis of placebo-controlled studies. J Clin Psychopharmacol. 1999;19(5):427-434. doi:10.1097/00004714199910000-00006

31. Fava M, Rosenbaum JF, McGrath PJ, Stewart JW, Amsterdam JD, Quitkin FM. Lithium and tricyclic augmentation of fluoxetine treatment for resistant major depression: a double-blind, controlled study. Am J Psychiatry. 1994;151(9):1372-1374.

32. Baumann P, Nil R, Souche A, et al. A double-blind, placebo-controlled study of citalopram with and without lithium in the treatment of therapy-resistant depressive patients: a clinical, pharmacokinetic, and pharmacogenetic investigation. $J$ Clin Psychopharmacol. 1996;16(4):307-314. doi:10.1097/00004714199608000-00006

33. Nelson JC, Baumann P, Delucchi K, Joffe R, Katona C. A systematic review and meta-analysis of lithium augmentation of tricyclic and second generation antidepressants in major depression. $J$ Affect Disord. 2014;168:269-275. doi:10.1016/j.jad.2014.05.053

34. U.S. Food and Drug Administration. West-Ward Pharmaceuticals. Lithium and Lithium carbonate [package insert]; 2018. Available from: https:// www.accessdata.fda.gov/drugsatfda_docs/1abel/2020/ 017812s034,018421s033,018558s028lbl.pdf. Accessed February 17, 2020

35. Treuer T, Liu CY, Salazar G, et al. Use of antidepressants in the treatment of depression in Asia: guidelines, clinical evidence, and experience revisited. Asia Pac Psychiatry. 2013;5(4):219-230. doi:10.1111/appy.12090

36. Henssler J, Bschor T, Baethge C. Combining antidepressants in acute treatment of depression: a meta-analysis of 38 studies including 4511 patients. Can J Psychiatry. 2016;61(1):29-43. doi:10.1177/ 0706743715620411

37. Connolly KR, Thase ME. If at first you don't succeed: a review of the evidence for antidepressant augmentation, combination and switching strategies. Drugs. 2011;71(1):43-64. doi:10.2165/11587620000000000-00000

38. Zhou X, Ravindran AV, Qin B, et al. Comparative efficacy, acceptability, and tolerability of augmentation agents in treatment-resistant depression: systematic review and network meta-analysis. J Clin Psychiatry. 2015;76(4):e487-e498. doi:10.4088/JCP.14r09204

39. Janssen. Janssen announces U.S. FDA approval of SPRAVATO ${ }^{\text {TM }}$ (esketamine) CIII nasal spray for adults with treatment-resistant depression (TRD) who have cycled through multiple treatments without relief; 2019. Available from: https://www.janssen.com/janssen-announces-us-fdaapproval-spravato-esketamine-ciii-nasal-spray-adults-treatment-resistant. Accessed November 23, 2019.
40. European Medicines Agency. Spravato: EPAR - product information; 2019. Available from: https:/www.ema.europa.eu/en/documents/pro duct-information/spravato-epar-product-information_en.pdf. Accessed October 15, 2020.

41. U.S. Food and Drug Administration. Drugs@FDA: FDA-Approved Drugs (SPRAVATO); 2019. Available from: https:/www.accessdata. fda.gov/drugsatfda_docs/label/2020/211243s004lbl.pdf. Accessed October 15, 2020.

42. Kim J, Farchione T, Potter A, Chen Q, Temple R. Esketamine for treatment-resistant depression - First FDA-approved antidepressant in a new class. $N$ Engl $J$ Med. 2019;381(1):1-4. doi:10.1056/ NEJMp1903305

43. U.S. Food and Drug Administration. Janssen Pharmaceuticals. SPRAVATO $^{\mathrm{TM}}$ (esketamine) nasal spray, CIII [package insert]; 2019. Available from: https://www.janssenlabels.com/package-insert /product-monograph/prescribing-information/SPRAVATO-pi.pdf. Accessed February 17, 2020.

44. Popova V, Daly EJ, Trivedi M, et al. Efficacy and safety of flexibly dosed esketamine nasal spray combined with a newly initiated oral antidepressant in treatment-resistant depression: a randomized double-blind active-controlled study. Am J Psychiatry. 2019;176 (6):428-438. doi:10.1176/appi.ajp.2019.19020172

45. Daly EJ, Trivedi MH, Janik A, et al. Efficacy of esketamine nasal spray plus oral antidepressant treatment for relapse prevention in patients with treatment-resistant depression: a randomized clinical trial. JAMA Psychiatry. 2019;76(9):893-903. doi:10.1001/ jamapsychiatry.2019.1189

46. Sanacora G, Frye MA, McDonald W, et al. A consensus statement on the use of ketamine in the treatment of mood disorders. JAMA Psychiatry. 2017;74(4):399-405. doi:10.1001/jamapsychia try.2017.0080

47. Szarmach J, Cubała WJ, Włodarczyk A, Wiglusz MS. Short-term ketamine administration in treatment-resistant depression: focus on cardiovascular safety. Psychiatr Danub. 2019;31(Suppl 3):585-590.

48. Włodarczyk A, Cubała WJ, Szarmach J, Małyszko A, Wiglusz MS Short-term ketamine administration in treatment-resistant depression patients: focus on adverse effects on the central nervous system. Psychiatr Danub. 2019;31(Suppl 3):530-533.

49. Liang HJ, Ungvari GS, Lee TSH, Tang WK. Ketamine addiction. Dual Diagn Open Access. 2018;3:3. doi:10.21767/2472-5048.100037

50. Feng LY, Wada K, Chung H, Han E, Li JH. Comparison of legislative management for new psychoactive substances control among Taiwan, South Korea, and Japan. Kaohsiung J Med Sci. 2019.

51. Tan TB, Nandhakumar G Ketamine antidepressant: breakthrough or potential hazard?; 2018. Available from: https://www.rsis.edu.sg/wpcontent/uploads/2018/03/CO18044.pdf. Accessed November 23, 2019.

52. Li JH, Kasinather V, Cheung YW, et al. To use or not to use: an update on licit and illicit ketamine use. Subst Abuse Rehabil. 2011;2:11-20. doi:10.2147/SAR.S15458

53. Kubitz N, Mehra M, Potluri RC, Garg N, Cossrow N. Characterization of treatment resistant depression episodes in a cohort of patients from a US commercial claims database. PLoS One. 2013;8(10):e76882. doi:10.1371/journal.pone.0076882

54. Williams N, Simpson AN, Simpson K, Nahas Z. Relapse rates with long-term antidepressant drug therapy: A meta-analysis. Hum Psychopharmacol. 2009;24(5):401-408. doi:10.1002/hup.1033

55. Glue P, Donovan MR, Kolluri S, Emir B. Meta-analysis of relapse prevention antidepressant trials in depressive disorders. Aust $\begin{array}{lllll}N & Z & J & \text { Psychiatry. 2010;44(8):697-705. doi:10.3109/000486 }\end{array}$ 71003705441

56. Geddes JR, Carney SM, Davies C, et al. Relapse prevention with antidepressant drug treatment in depressive disorders: a systematic review. Lancet. 2003;361(9358):653-661. doi:10.1016/S01406736(03)12599-8 
57. U.S. Food and Drug Administration. Psychopharmacologic Drugs Advisory Committee (PDAC) and Drug Safety and Risk Management (DSaRM) Advisory Committee Meeting February 12; 2019. Available from: https://www.fda.gov/media/121376/download. Accessed November 24, 2019.

58. National Institute for Health and Care Excellence - Depression: the treatment and management of depression in adults; 2009. Available from: https://www.nice.org.uk/guidance/cg90/documents/depressionin-adults-update-full-guideline-prepublication2. Accessed November 24, 2019.

59. Kennedy SH, Lam RW, McIntyre RS, et al. Canadian Network for Mood and Anxiety Treatments (CANMAT) 2016 clinical guidelines for the management of adults with major depressive disorder: section 3. Pharmacological treatments. Can J Psychiatry. 2016;61 (9):540-560. doi:10.1177/0706743716659417

60. Alexopoulos GS, Katz IR, Reynolds CF 3rd, Carpenter D, Docherty JP. The expert consensus guideline series. Pharmacotherapy of depressive disorders in older patients. Postgrad Med. 2001; Spec No Pharmacotherapy:1-86.

61. Kok RM, Reynolds CF 3rd. Management of depression in older adults: a review. JAMA. 2017;317(20):2114-2122. doi:10.1001/ jama.2017.5706

62. Leiknes KA, Jarosh-von Schweder L, Hoie B. Contemporary use and practice of electroconvulsive therapy worldwide. Brain Behav. 2012;2(3):283-344. doi:10.1002/brb3.37

63. Hemphill R, Walter W, Grey J. The treatment of mental disorders by electrically induced convulsions. $B r \quad J \quad$ Psychiatry. 1941;87 (367):256-275.

64. Chanpattana W, Kramer BA, Kunigiri G, Gangadhar BN, Kitphati R, Andrade C. A survey of the practice of electroconvulsive therapy in Asia. J ECT. 2010;26(1):5-10. doi:10.1097/YCT.0b013e3181a74368

65. World Health Organization. WHO Resource book on mental health, human rights and legislation; 2005. Available from: https://ec.europa. eu/health/sites/health/files/mental_health/docs/who_resource_book_ en.pdf. Accessed November 24, 2019.

66. Lam RW, McIntosh D, Wang J, et al. Canadian Network for Mood and Anxiety Treatments (CANMAT) 2016 clinical guidelines for the management of adults with major depressive disorder: section 1 . Disease burden and principles of care. Can J Psychiatry. 2016;61 (9):510-523. doi:10.1177/0706743716659416

67. Milev RV, Giacobbe P, Kennedy SH, et al. Canadian Network for Mood and Anxiety Treatments (CANMAT) 2016 clinical guidelines for the management of adults with major depressive disorder: section 4. Neurostimulation treatments. Can J Psychiatry. 2016;61 (9):561-575. doi:10.1177/0706743716660033

68. National Institute for Health and Care Excellence - Depression in adults: recognition and management; 2018. Available from: https:// www.nice.org.uk/guidance/cg90. Accessed November 24, 2019.

69. Baghai TC, Moller HJ. Electroconvulsive therapy and its different indications. Dialogues Clin Neurosci. 2008;10(1):105-117.

70. Sackeim HA, Decina P, Kanzler M, Kerr B, Malitz S. Effects of electrode placement on the efficacy of titrated, low-dose ECT. Am J Psychiatry. 1987;144(11):1449-1455.

71. Jan Otto Ottosson J, Fink M. Ethics in Electroconvulsive Therapy. New York: Brunner-Routledge; 2004.

72. Petrides G, Fink M, Husain MM, et al. ECT remission rates in psychotic versus nonpsychotic depressed patients: a report from CORE. $J$ ECT. 2001;17(4):244-253. doi:10.1097/00124509200112000-00003

73. UK ECT Review Group. Efficacy and safety of electroconvulsive therapy in depressive disorders: a systematic review and meta-analysis. Lancet. 2003;361(9360):799-808. doi:10.1016/ S0140-6736(03)12705-5

74. Pagnin D, de Queiroz V, Pini S, Cassano GB. Efficacy of ECT in depression: a meta-analytic review. J ECT. 2004;20(1):13-20. doi:10.1097/00124509-200403000-00004
75. Kho KH, van Vreeswijk MF, Simpson S, Zwinderman AH. A meta-analysis of electroconvulsive therapy efficacy in depression. $J$ ECT. 2003;19(3):139-147. doi:10.1097/00124509-20030900000005

76. Schutter DJ. Quantitative review of the efficacy of slow-frequency magnetic brain stimulation in major depressive disorder. Psychol Med. 2010;40(11):1789-1795. doi:10.1017/S003329171000005X

77. Berlim MT, Van den Eynde F, Jeff Daskalakis Z. Clinically meaningful efficacy and acceptability of low-frequency repetitive transcranial magnetic stimulation (rTMS) for treating primary major depression: a meta-analysis of randomized, double-blind and sham-controlled trials. Neuropsychopharmacology. 2013;38 (4):543-551. doi:10.1038/npp.2012.237

78. Berlim MT, Van den Eynde F, Daskalakis ZJ. A systematic review and meta-analysis on the efficacy and acceptability of bilateral repetitive transcranial magnetic stimulation (rTMS) for treating major depression. Psychol Med. 2013;43(11):2245-2254. doi:10.1017/ S0033291712002802

79. McClintock SM, Reti IM, Carpenter LL, et al. Consensus recommendations for the clinical application of repetitive transcranial magnetic stimulation (rTMS) in the treatment of depression. J Clin Psychiatry. 2018;79(1):35-48. doi:10.4088/JCP.16cs10905

80. Slotema CW, Blom JD, Hoek HW, Sommer IE. Should we expand the toolbox of psychiatric treatment methods to include Repetitive Transcranial Magnetic Stimulation (rTMS)? A meta-analysis of the efficacy of rTMS in psychiatric disorders. J Clin Psychiatry. 2010;71 (7):873-884. doi:10.4088/JCP.08m04872gre

81. Berlim MT, Van den Eynde F, Daskalakis ZJ. Efficacy and acceptability of high frequency repetitive transcranial magnetic stimulation (rTMS) versus electroconvulsive therapy (ECT) for major depression: a systematic review and meta-analysis of randomized trials. Depress Anxiety. 2013;30(7):614-623. doi:10.1002/da.22060

82. Ontario HQ. Repetitive transcranial magnetic stimulation for treatment-resistant depression: a systematic review and meta-analysis of randomized controlled trials. Ont Health Technol Assess Ser. 2016;16(5):1-66.

83. Muller HHO, Moeller S, Lucke C, Lam AP, Braun N, Philipsen A. Vagus nerve stimulation (VNS) and other augmentation strategies for therapy-resistant depression (TRD): review of the evidence and clinical advice for use. Front Neurosci. 2018;12:239. doi:10.3389/ fnins.2018.00239

84. Ijaz S, Davies P, Williams CJ, Kessler D, Lewis G, Wiles N. Psychological therapies for treatment-resistant depression in adults. Cochrane Database Syst Rev. 2018;5:CD010558.

85. de Maat SM, Dekker J, Schoevers RA, de Jonghe F. Relative efficacy of psychotherapy and combined therapy in the treatment of depression: a meta-analysis. Eur Psychiatry. 2007;22(1):1-8. doi:10.1016/j. eurpsy.2006.10.008

86. Cuijpers P, Dekker J, Hollon SD, Andersson G. Adding psychotherapy to pharmacotherapy in the treatment of depressive disorders in adults: a meta-analysis. J Clin Psychiatry. 2009;70(9):1219-1229. doi:10.4088/JCP.09r05021

87. Bauer M, Severus E, Kohler S, et al. World Federation of Societies of Biological Psychiatry (WFSBP) guidelines for biological treatment of unipolar depressive disorders. part 2: maintenance treatment of major depressive disorder - Update 2015. World J Biol Psychiatry. 2015;16 (2):76-95. doi:10.3109/15622975.2014.1001786

88. Bennabi D, Charpeaud T, Yrondi A, et al. Clinical guidelines for the management of treatment-resistant depression: french recommendations from experts, the French Association for Biological Psychiatry and Neuropsychopharmacology and the fondation FondaMental. BMC Psychiatry. 2019;19(1):262. doi:10.1186/s12888-019-2237-x

89. Zhang Q, DiBernardo A, Heerlein K, et al. Association of treatment resistant depression with healthcare resource utilization and physician satisfaction with disease management. Value Health. 2018;21:S188. doi:10.1016/j.jval.2018.04.1270 


\section{Publish your work in this journal}

Neuropsychiatric Disease and Treatment is an international, peerreviewed journal of clinical therapeutics and pharmacology focusing on concise rapid reporting of clinical or pre-clinical studies on a range of neuropsychiatric and neurological disorders. This journal is indexed on PubMed Central, the 'PsycINFO' database and CAS, and is the official journal of The International Neuropsychiatric Association (INA). The manuscript management system is completely online and includes a very quick and fair peer-review system, which is all easy to use. Visit http://www.dovepress.com/testimonials.php to read real quotes from published authors.

Submit your manuscript here: https://www.dovepress.com/neuropsychiatric-disease-and-treatment-journal 